\title{
Invasional Interference Due to Similar Inter- and Intraspecific Competition Between Invaders May Affect Management
}

\author{
Emily S.J. Rauschert \\ Cleveland State University, e.rauschert@csuohio.edu \\ Katriona Shea \\ Pennsylvania State University
}

Follow this and additional works at: https://engagedscholarship.csuohio.edu/scibges_facpub

Part of the Biology Commons, and the Weed Science Commons

How does access to this work benefit you? Let us know!

Publisher's Statement

Open Access (C2012 by the Ecological Society of America

\section{Recommended Citation}

Rauschert, E.S.J., and K. Shea. (2012). Invasional interference due to similar inter- and intraspecific competition between invaders may affect management. Ecological Applications 22: 1413-1420.

This Article is brought to you for free and open access by the Biological, Geological, and Environmental Sciences Department at EngagedScholarship@CSU. It has been accepted for inclusion in Biological, Geological, and Environmental Faculty Publications by an authorized administrator of EngagedScholarship@CSU. For more information, please contact library.es@csuohio.edu. 


\title{
Invasional interference due to similar inter- and intraspecific competition between invaders may affect management
}

\author{
Emily Sofia Jalics Rauschert ${ }^{1,3}$ and Katriona Shea ${ }^{2}$ \\ ${ }^{1}$ IGDP in Ecology and Department of Crop and Soil Sciences, 116 ASI Building, Pennsylvania State University, \\ University Park, Pennsylvania 16802 USA \\ ${ }^{2}$ Department of Biology and IGDP in Ecology, 208 Muller Laboratory, Pennsylvania State University, \\ University Park, Pennsylvania 16802 USA
}

\begin{abstract}
As the number of biological invasions increases, the potential for invaderinvader interactions also rises. The effect of multiple invaders can be superadditive (invasional meltdown), additive, or subadditive (invasional interference); which of these situations occurs has critical implications for prioritization of management efforts. Carduus nutans and $C$. acanthoides, two congeneric invasive weeds, have a striking, segregated distribution in central Pennsylvania, USA. Possible hypotheses for this pattern include invasion history and chance, direct competition, or negative interactions mediated by other species, such as shared pollinators. To explore the role of resource competition in generating this pattern, we conducted three related experiments using a response-surface design throughout the life cycles of two cohorts. Although these species have similar niche requirements, we found no differential response to competition between conspecifics vs. congeners. The response to combined density was relatively weak for both species. While direct competitive interactions do not explain the segregated distributional patterns of these two species, we predict that invasions of either species singly, or both species together, would have similar impacts. When prioritizing which areas to target to prevent the spread of one of the species, it is better to focus on areas as yet unaffected by its congener; where the congener is already present, invasional interference makes it unlikely that the net effect will change.
\end{abstract}

Key words: Carduus acanthoides; Carduus nutans; central Pennsylvania USA; co-invasion competition; congeners; invasional interference; invader-invader interactions; invasion ecology; invasive species management; thistles.

\section{INTRODUCTION}

Invasive species can have profound impacts on ecosystems in their invaded ranges (Mooney and Hobbs 2000). Competition among plants is thought to be particularly important, as plants often have very similar niche requirements; this may be one important way in which the effects of invasive species are expressed. Many studies have examined interactions between native and exotic species (e.g., Meekins and McCarthy 1999, Byers 2000, Seabloom et al. 2003). However, despite long-term recognition of the potential for invader-invader interactions (Elton 1958), few studies have focused on interactions between invasive species at the same trophic level (but see Laterra and Bazzalo [1999] and examples from the marine literature: Ramsay et al. 2008, Griffen and Byers 2009, Griffen et al. 2011). Invaders can compete and influence each other's dynamics, and hence invasion outcomes.

The combined effects of two invaders can be super-

Manuscript received 23 November 2011; revised 17 January 2012; accepted 23 January 2012. Corresponding Editor: R. A. Hufbauer.

${ }^{3}$ E-mail: erauschert@psu.edu additive, additive, or subadditive. The invasional meltdown hypothesis (Simberloff 1999) encapsulates the superadditive effect: because two invasives have positive impacts on each other, they are more successful as invaders, both either occupying more area or existing at higher densities, and having larger impacts on the ecosystem. If invaders have little impact on each other, their effects would mainly be additive. Yang et al. (2011) have recently proposed the possibility of invasional interference, where two invaders impact each other negatively and thus neither exerts as strong an influence on the native ecosystem as it would alone. Invasional interference occurs when both species perform less well when together than when alone, for example if they both exhibit reduced proportional seed set when pollinated by a common pollinator (Yang et al. 2011). Similarly, when the invasive European green crab was largely displaced by a second invasive, the Asian shore crab, the overall effect on the native bivalve prey species was similar, despite a higher density of the Asian shore crab (Lohrer and Whitlatch 2002). Thus, reductions in either species due to competition could still lead to a similar level of combined invasion impact. In some cases they may even have a lower net impact, as has been observed using multiple nonnative biocontrol agents to control the

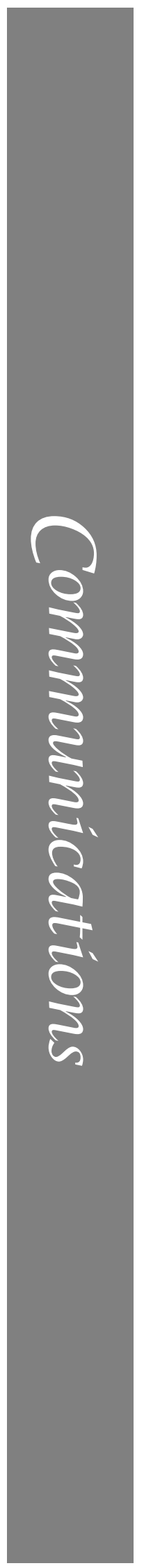


invasive plant Centauria stoebe; adding the gall-inducing fly Urophora affinis when Larinus minutus, a weevil, was already present led to less overall $C$. stoebe seed destruction than if L. minutus were present alone (Crowe and Bourchier 2006).

Which of these cases occurs is essential for prioritization of management efforts, which should be based on impacts on the local ecosystem rather than nonnative status (Davis et al. 2011). In the case of invasional interference, the second invader may lead to relatively minor additional negative impacts, and hence the prioritization of this ecosystem for management is unaffected. On the other hand, if there is a superadditive (invasional meltdown) effect, preventing the invasion of the second species should have a high priority.

Carduus nutans L. and C. acanthoides L., two very similar invasive species, have a strongly segregated distribution in central Pennsylvania (Allen and Shea 2006). The cause(s) of this distributional difference is unknown, but it does not appear to be driven by different abiotic conditions or management practices (Allen and Shea 2006, Rauschert et al. 2012). The role of intraspecific thistle competition has not been well studied (Milbrath and Nechols 2004). Interspecific competition between these species is also not well understood, though Warwick et al. (1990) found that $C$. nutans was a more aggressive competitor than $C$. acanthoides in the greenhouse, suggesting that $C$. nutans might eventually replace $C$. acanthoides.

We examined competition between the two species as a possible factor affecting their spatial distribution (Bullock et al. 2000, Freckleton and Watkinson 2000), as well as to elucidate the potential for interactions that might alter predictions about invasion success made from single-species studies. We studied the full life cycle, as competition at early life-history stages can lead to segregation and lack of competition at later stages, which in turn can lead to misinterpretations of the role of competition (Kubota and Hara 1996). We used three two-cohort response-surface design field experiments to investigate interactions between $C$. nutans and $C$. acanthoides at different densities and different lifehistory stages. The first experiment involved planting seeds in known locations (seed placement experiment). Second, a seedling placement experiment was conducted, in which seedlings were transplanted to known locations, to ensure the planned proportions at later life stages. Finally, as there was an upper limit to the densities that we could investigate with these approaches due to limitations in marking individual seed/seedling locations, we also performed a seed scattering experiment to examine higher densities. In all three experiments we hypothesized that $C$. nutans would have a stronger effect on $C$. acanthoides than the reverse, at least at the earliest stages, due to early growth advantages arising from its larger seed size.

\section{Methods \\ Species description}

Carduus nutans and C. acanthoides are herbaceous monocarpic perennials (Desrochers et al. 1988). Individuals of both species can produce thousands of seeds; there is no record of vegetative reproduction (Desrochers et al. 1988). Seed set occurs during summer and fall with the next generation emerging primarily the same fall in suitable microsites (Ruggiero and Shea 2011). It is difficult to tell the species apart at the seedling and rosette stages (McCarty et al. 1969); after overwintering, species differences such as leaf shape and hairiness are more pronounced. Both species occur in similar habitats, primarily in pastures and roadsides (Batra 1978), and they co-occur in some locations in their native (Eurasia) and invaded ranges.

\section{Site description}

All field experiments were performed at the Russell E. Larson Agricultural Center at Rock Springs $\left(40^{\circ} 71^{\prime} 1^{\prime \prime}\right.$ $\mathrm{N}, 77^{\circ} 94^{\prime} 2^{\prime \prime} \mathrm{W}$ ) in the Ridge and Valley physiographic province of Pennsylvania, USA. The site is a former pasture, ungrazed for more than a decade, with mostly weedy grasses and dicots present. In the summer preceding the planting of each cohort of each experiment, seeds were collected from naturally occurring populations from within the areas known to have only one species present (near Carlisle, Pennsylvania, for $C$. nutans, and State College, Pennsylvania, for C. acanthoides). Seeds were removed from flower heads, sifted using mesh screens to remove flat, nonviable seeds, and used in experiments that same fall for maximum seed viability.

\section{Experimental design}

We conducted a response-surface design experiment (Inouye 2001) with a group of substitution series at different densities to best estimate competition coefficients and population growth parameters. All experiments consisted of a randomized complete-block design involving five relative composition treatments $(C$. nutans:C. acanthoides ratios of 100:0, 75:25, 50:50, $25: 75,0: 100)$ at three different densities (high, medium, and low), leading to 15 plot types. These two thistle species are roughly equivalent in size, so replacing one individual with a congeneric individual affects only composition, not overall density.

\section{Seed placement experiment}

The seed placement experiment involved planting seeds in known locations, in order to be certain of early species identity. In September 2003 and 2004, 15 plots, replicated in six blocks, were each planted with 16 individuals, regularly spaced on a four-by-four grid. The size of the plots was varied to create different densities: 100 seeds $/ \mathrm{m}^{2}$ (low density), 400 seeds $/ \mathrm{m}^{2}$ (medium density), and 2500 seeds $/ \mathrm{m}^{2}$ (high density). Each plot 
was placed in the middle of a $0.5 \times 0.5 \mathrm{~m}$ area in 2003 and a $2 \times 2 \mathrm{~m}$ area in 2004, leaving a border area of at least the same width as the spacing. Within each plot, each of the 16 locations was randomly assigned to either $C$. nutans or C. acanthoides, constrained by the number of individuals of each species necessary for the desired relative plot composition. Prior to the start of the experiment, the plots were tilled, as some level of disturbance is necessary for emergence (K. Shea, unpublished data), and only a limited number of other plants reinvaded the plots. Seeds were planted at a depth of $5 \mathrm{~mm}$, which enhances emergence (McCarty et al. 1969).

\section{Seedling placement experiment}

As emergence can be quite variable (E. Rauschert, unpublished data), we initiated an experiment with seedlings, in order to study specific proportions and densities at later life stages. In early September 2003 and 2004, seeds were planted individually in pots in a greenhouse and transplanted to the field after their true leaves had extended beyond their cotyledons for most individuals (after approximately three weeks). The field site was mowed once prior to initiation of the experiment. Six blocks were planned in each year, but due to poor emergence of $C$. nutans in the greenhouse, only five blocks were possible in 2003. As in the seed placement experiment, each plot consisted of 16 individuals placed in the center of a $2.5 \times 2.5 \mathrm{~m}$ area. The densities studied were 4,25 , and 100 thistles $/ \mathrm{m}^{2}$, again created by varying plot sizes.

\section{Seed scattering experiment}

In order to investigate higher thistle densities than could be individually marked, a similar response-surface experiment with six replicates was planted at the field site in the fall of 2004 and 2005. All plots were the same size $(20 \times 20 \mathrm{~cm})$, and density was varied by changing the numbers of seeds sown $(1000,2000$, and 4000 seeds/ $\mathrm{m}^{2}$ ). The lowest density is similar to that which would be found near a dispersing parent plant (O. Skarpaas, personal communication), and we chose to also investigate higher densities, as this has been shown to improve parameter estimation (Inouye 2001). A control treatment, with no sown seeds, allowed us to monitor background emergence. Each plot was tilled prior to planting to remove all other vegetation; only a few individuals of other plant species reinvaded the plots. Seeds were scattered haphazardly across the plots and covered lightly with soil.

\section{Data collection and analysis}

The seed placement experiment was monitored for emergence three times a week during the one-month peak-emergence period in September-October. All experiments were censused for presence/absence and size (longest leaf length and rosette diameter) in the fall and spring, and censused destructively for size and number of flower heads in July when plants were setting seed (completion of the life cycle). The seed and seedling placement experiments were terminated after the first summer, when all flowering individuals had been removed and the remaining plot compositions were no longer representative of the treatments. The seed scattering experiment had higher numbers of individuals planted; few plants flowered in the first year, leaving similar plot composition, so plots were left intact and monitored for a second year when more individuals flowered and set seed.

The average plot response for each species was the basic unit for analysis, to avoid pseudoreplication (Crawley 2002). Logistic regressions were examined for emergence, flowering success, and survivorship (Crawley 2002). Since overdispersion was present in the average number of heads produced and average days to emergence, these were analyzed using a quasi-GLM model, with the variance adjusted by multiplying the mean by the overdispersion parameter (Zuur et al. 2009), which performs well for ecological count data (Hoef and Boveng 2007, O'Hara and Kotze 2010). The combined density of both species and the proportion of the plot that was planted with the other species were the explanatory variables. At a given density, as the proportion of one species increased, the proportion of the other decreased. Densities were normalized to be between 0 and 1 , to facilitate comparison with the "proportion of other species" variable. Planting densities and proportions were used for analyses of emergence and survival, and actual densities and proportions present at the time of measurement were used for later life-history stages in experiments where the planting density and actual densities were potentially different. For the seedling-placement experiment, planted densities were always used, as survivorship was very high. Interactions between density and the proportion of the other species were only included if the coefficients were significant $(P<0.05)$. The block/year effect was included as a random effect using mixed models (glmmPQL in R). All analyses were performed using R (R Development Core Team 2008).

We focused on the measures most closely tied to fitness for a particular experiment (emergence and survival, and speed of emergence for experiments on earlier stages; proportion flowering, and number of flower heads produced for experiments on later stages). If a response variable was found to be positively related to the proportion of the other species present, we took this to mean that individuals had higher performance in plots with more heterospecifics vs. conspecifics, which implies that the strength of intraspecific competition was greater than interspecific competition. The only exception is for analyses of days to emergence, where a negative relationship implies that the average days to emergence was shorter.

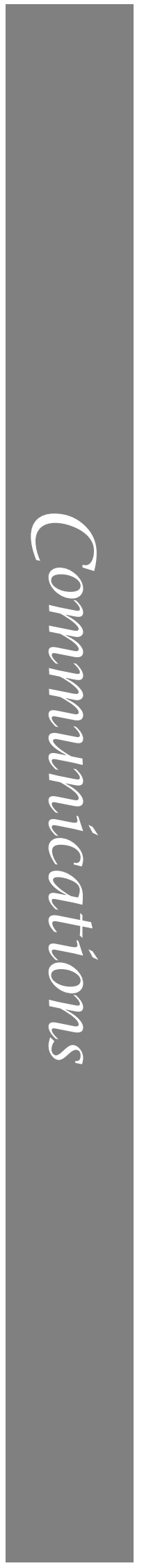




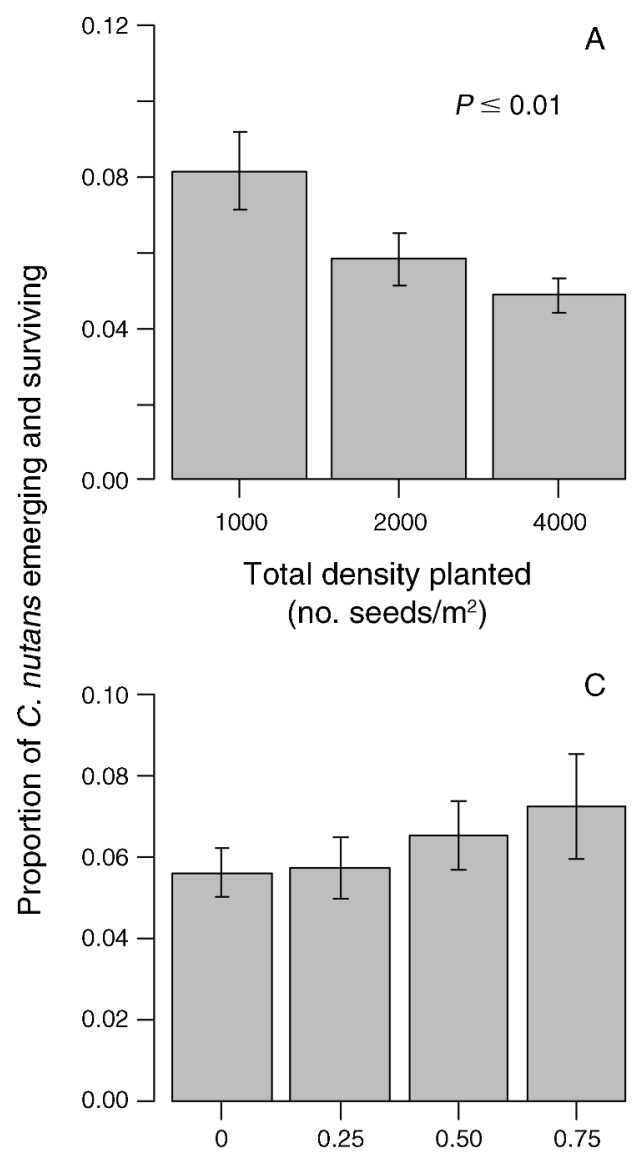

Proportion of $C$. acanthoides planted

A
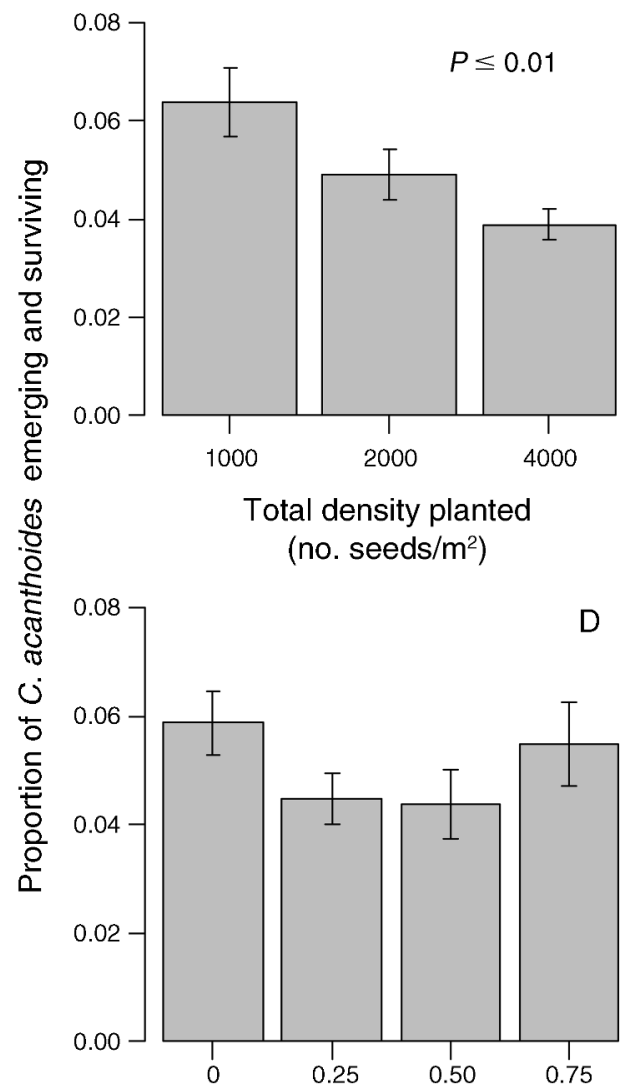

Proportion of $C$. nutans planted

FIG. 1. Seed-scattering experiment: the average response of emergence and survival until July by Carduus nutans and $C$. acanthoides, two congeneric invasive weeds, to density and the proportion of the other species planted (data are means \pm SE). (A, B) The proportions of $C$. nutans and $C$. acanthoides emerging and surviving decrease significantly with increasing density. $(\mathrm{C}, \mathrm{D})$ Emergence and survival of each thistle species in relation to the planting proportion of the other species; monoculture plots are on the left of the graph (with zero proportion of the other species planted). The proportion emerging and surviving until July is not significantly related to the proportion of other species planted. Thus there is no evidence of stronger interspecific competition relative to intraspecific competition.

\section{Results}

In the seed placement experiment, $52 \%$ of Carduus nutans and $41 \%$ of C. acanthoides emerged in 2003 (720 seeds planted for each species), whereas only $41 \%$ and $28 \%$ emerged in 2004, respectively. The mean time to emergence was similar for both species (14 days). There were large differences in plant performance between blocks. Analyses of the average days to emergence did not demonstrate strong impacts of the proportion of the other species present. This was only significant for the proportion of $C$. nutans emerging, where it had a negative effect; however, this effect appears to be largely driven by the $75 \%$ C. acanthoides category, which had lower $C$. nutans emergence. There was a significant interaction of density by proportion of the other species in the model of $C$. acanthoides emergence; density had a negative effect in monoculture but a higher proportion emerged as the proportion of $C$. nutans increased and density was higher. Density had a negative impact on the days to $C$. acanthoides emergence, which implies generally faster emergence at higher densities. There were no significant relationships with density for $C$. nutans.

In the seedling placement experiment nearly all individuals survived from the fall to the next summer (542/581 and 692/720 of C. nutans in the first and second cohorts, respectively, and $608 / 619$ and $688 / 720$ of $C$. acanthoides), but the two years of this experiment had very different flowering rates: $49 \%$ of C. nutans and $38 \%$ of C. acanthoides flowered in the first cohort, while only $13 \%$ and $6 \%$, respectively, flowered in the second cohort. The proportion flowering was not significantly related to density or to the proportion of the other species present. The number of flower heads produced by $C$. nutans was 

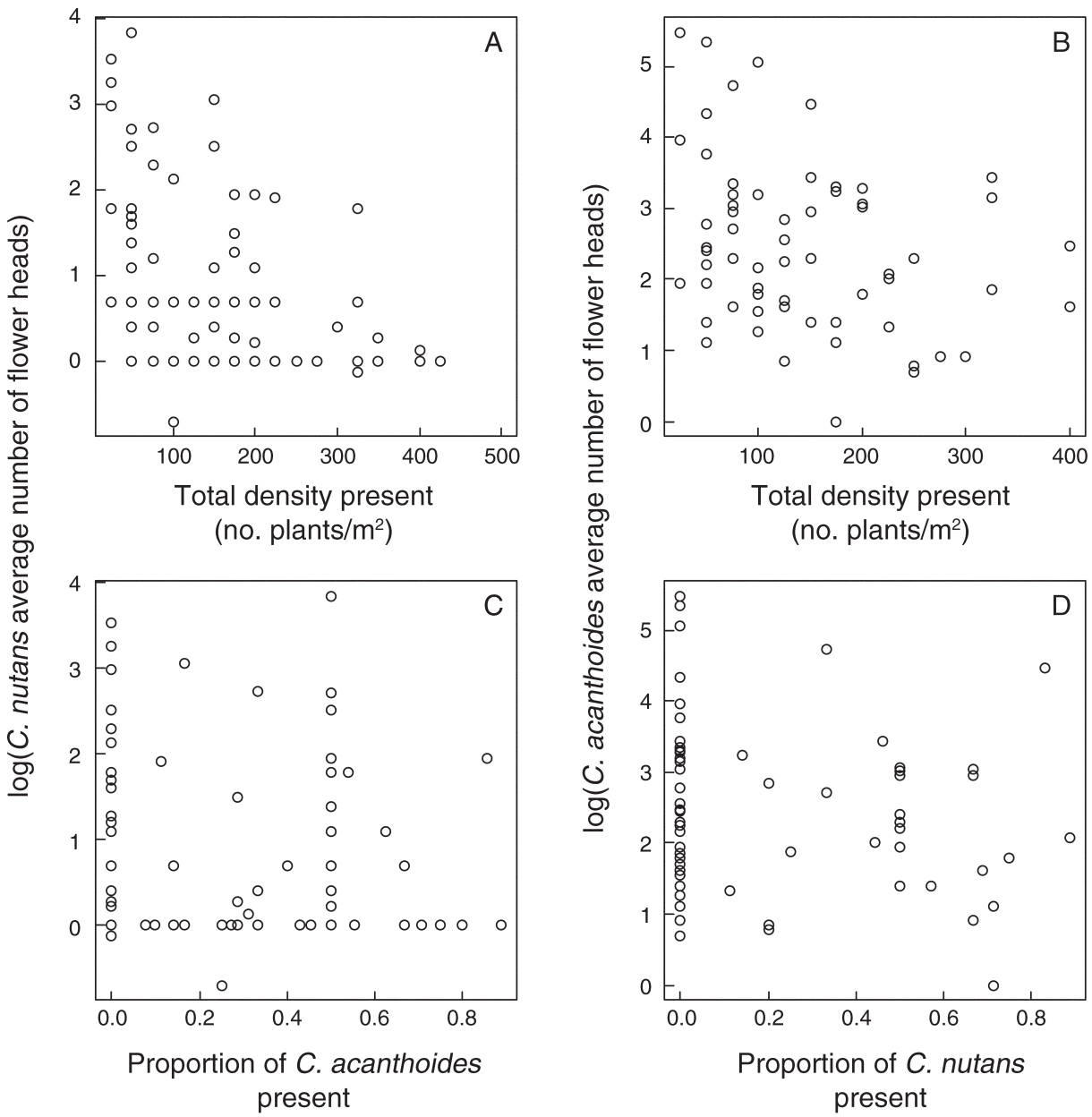

FIG. 2. Seed-scattering experiment: the number of flower heads produced in both cohorts in response to actual densities and actual proportions of the other species present. For both species, (A, B) density had a significant negative effect on the number of heads produced, but $(C, D)$ there was no significant effect of the proportion of the other species present (i.e., no evidence for stronger interspecific competition). In this figure, Carduus acanthoides results are from the second year of each cohort due to extremely low proportions flowering in the first year.

positively affected by increased proportion of $C$. acanthoides. The number of flower heads produced was negatively related to overall density for both species (Appendix: Fig. A1).

In the seed scattering experiment, of the 4200 seeds planted in each cohort, there were 358 C. nutans and 245 C. acanthoides in July of the first year of the first cohort, and 248 and 183 seeds, respectively, in the second cohort. No emergence was observed in the control plots. In the first year of the first cohort only $9.5 \%$ of emerged C. nutans and $1.6 \%$ of C. acanthoides flowered, but by the second year $24 \%$ and $22 \%$, respectively, were flowering. In year one of cohort two there was negligible flowering, but by the second year $76 \%$ of $C$. nutans and $60 \%$ of $C$. acanthoides flowered.

In the seed scattering experiment, overall plot density had a negative impact on emergence and survival to July and on the number of flower heads produced for both species, but density had a positive effect on the proportion flowering in the second year (Figs. 1 and 2). The proportion of the other species present was not significantly related to any attribute for either species (Table 1).

\section{DisCUSSION}

Competition is thought to be important for plants because most plants require the same resources, such as nutrients (i.e., water and macronutrients such as nitrogen and phosphorus), light and space (Tilman 1997). In general, the more similar plants are, the more intense the level of competition between them may be (Johansson and Keddy 1991). The strongest evidence we observed for density dependence was from later life stages at high densities. Importantly, competition from the other thistle species does not seem to differ from intraspecific competition; our hypothesis of a stronger

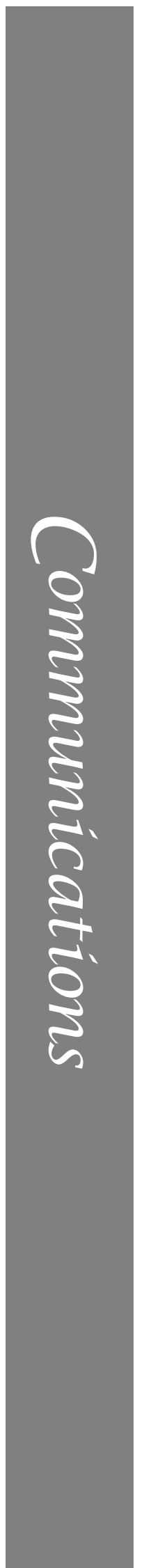


TABLE 1. Key statistical results for the three two-cohort response-surface competition experiments involving the invasive thistle species Carduus nutans and C. acanthoides.

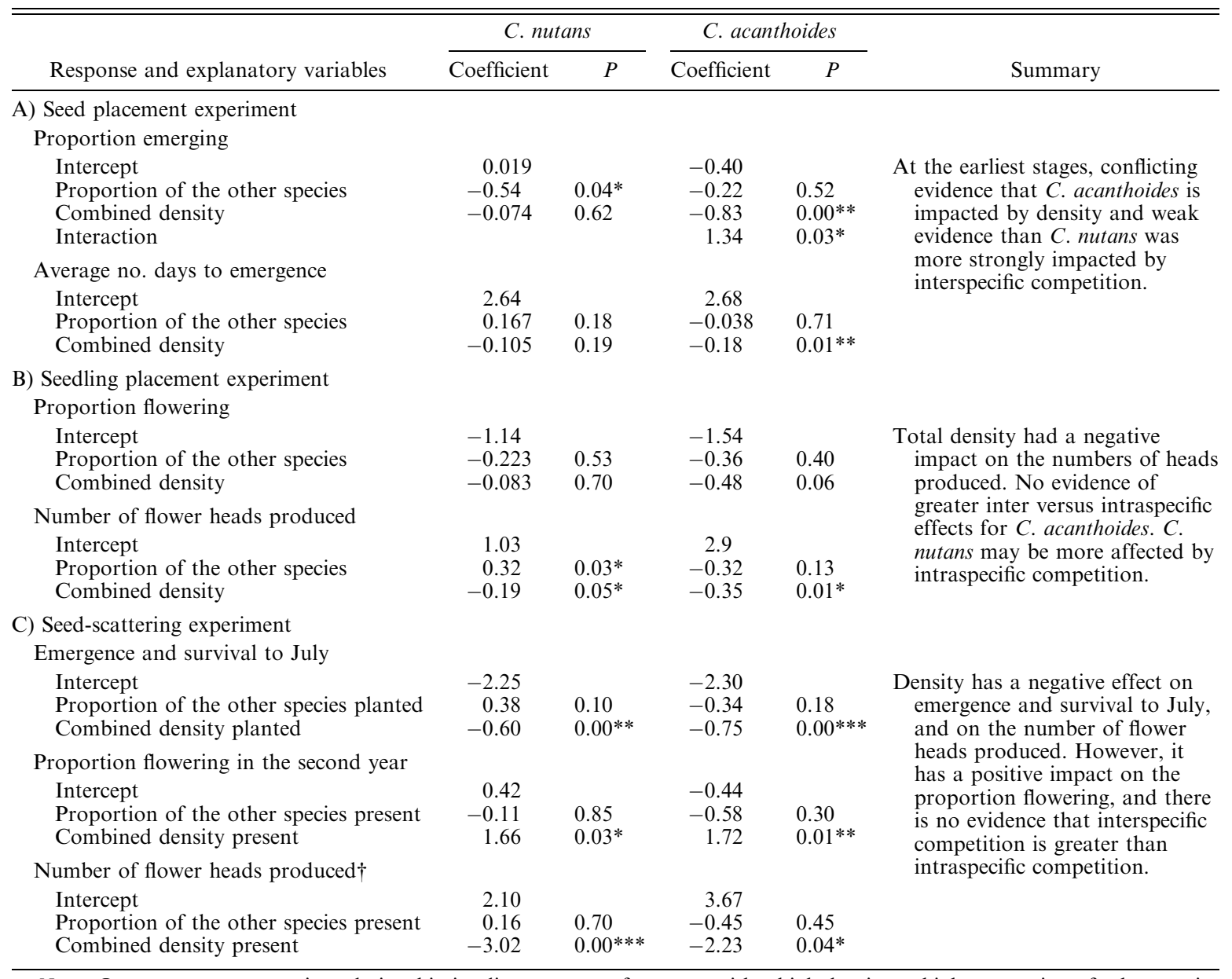

Notes: In most cases, a negative relationship implies poorer performance with a high density or high proportion of other species present; for the average days to emergence, a negative relationship implies faster emergence.

$* P \leq 0.05 ; * * P \leq 0.01 ; * * * P \leq 0.001$.

competitive effect of Carduus nutans was not supported. We found most evidence for density dependence in the seed scattering experiment, where we investigated densities far higher than would typically be found under a parent plant.

Negative pollinator-mediated interactions have been observed between these two species by Yang et al. (2011), who found that proportional seed set was reduced in mixed stands vs. pure stands for both species. However, this did not translate into a plant-level fitness effect, as similar numbers of seeds per individual were still produced. It is possible that the fitness of seeds produced in mixed stands is lower. Yang et al. (2011) found that more pollination events occurred within a single plant in mixed arrays, but the performance of seed from different types of crosses, and the hypothesis that selfed seeds are less fit, remains to be tested. Nonetheless, even in mixed stands, the flowering phenology overlap of these two species is not complete in central Pennsylvania (USA), and both species flower alone for significant periods of time. In our experiments, concerns about potentially introducing an invasive species not present locally $(C$. nutans) precluded allowing experimental plants to disperse seed so that we could follow the next generation. However, we did examine the effects of maternal competitive environment on seeds in the greenhouse. We observed no differences between maternal inter- and intraspecific competition, and the overall germination rates were relatively high (Rauschert 2006). Our findings are also consistent with classical reviews of competition: the strength of interspecific and intraspecific competitions among primary producers was found to be similar, regardless of the level of productivity (Gurevitch et al. 1992), and similar results were found specifically for plants (Goldberg and Barton 1992).

We observed considerable variation in individual plant performance. For example, in Fig. 2 (a, b), at low densities, there is a wide range of numbers of flower heads produced, with less variation in the lower numbers observed at higher densities; it appears that density 
dependence may lead to an upper boundary on plant performance, with many individuals at lower densities performing well below this level as a result of factors other than density. This "envelope effect" has also been observed with other plants (Goldberg 1987, Guo et al. 1998). Some of this may have been mediated by responses to underlying resource heterogeneities, to other vegetation (though the seed-initiated experiments were conducted on bare ground), or even via indirect interactions between the two invasive species (White et al. 2006). Even if there is a strong mean effect of competition, given enough variation in response to competition, inferior competitors may still be able to persist for extended periods because they sometimes are able to succeed (Chesson 2000) This high variation also suggests that competition between these species would be unlikely to lead to a stable segregated pattern, as the degree of inter vs. intraspecific competition experienced by individuals can vary and hence lead to different outcomes.

Sfenthourakis et al. (2006), in a meta-analysis of species co-occurrences, found no evidence for widespread competition among congeneric species. They also found no evidence for stronger associations between species pairs. They suggest that patterns observed are more a result of history or habitat preferences. There are no clear differing habitat preferences for these two thistles (Allen and Shea 2006), and it appears that, at the scale of a field, aggregation in favorable sites has a stronger effect than small-scale interspecific competition (Rauschert et al. 2012). Slow spread rates projected for wind dispersal of these species suggest that human activity may be responsible for regional spread (Skarpaas and Shea 2007). Thus historical invasion patterns may be the cause of the segregated pattern observable today. Due to the lack of stronger direct interspecific competitive effects between Carduus nutans and $C$. acanthoides documented in this study, we would expect the segregation of these two species to degrade over time, unless other factors are involved in maintaining this pattern, as discussed above.

In conclusion, we found no strong evidence for stronger interspecific competition between $C$. nutans and $C$. acanthoides, but some evidence for combined density dependence. It seems that for these thistle species, intraspecific competition is similar to interspecific competition, and that the response to density may be small under usual field conditions. For the Carduus system, the concept of invasional interference most closely applies; certainly the risk of invasional meltdown (Simberloff 1999) is low for this pair of invaders. Both species respond somewhat to the overall density of Carduus thistles, so we would predict that one species invading into an area occupied by the other might change their ratios, but would not greatly impact the overall density of thistles. In terms of management, priority should be given to keeping Carduus thistles out of areas that are thistle-free; if an area is already invaded by one species, it seems relatively unlikely that the subsequent invasion of the other will greatly increase the net impact on the invaded community.

More broadly, our results suggest important general insights for invasive-species management. Biotic resistance, typically thought of as the native community's ability to repel invasion, may lead to reduced invasion success, both in terms of the ability to invade and the abundance attained by invaders (Levine et al. 2004). However, many communities are already heavily invaded by nonnatives, often by species with similar traits (as is the case in our study). Based on our findings, we argue that nonnative community members may also play a large role in biotic resistance. Taking such invasional interference into account will be critical for successful invasive species management.

\section{ACKNOWLEDGMENTS}

This research was partially supported by USDA grant 200235320-1228 to K. Shea and a NASA Space Grant Fellowship to E. Rauschert. We thank: T. Omeis, R. Lease, S. Smiles, and S. Harkcom for logistical support; O. Bjørnstad and O. Skarpaas for statistical suggestions; and Z. Sezen, E. Dlugosz, J. Mellon, J. Butterbaugh, A. Reese, and S. Selego for assistance in the field.

\section{Literature Cited}

Allen, M., and K. Shea. 2006. Spatial segregation of congeneric invaders in central Pennsylvania, USA. Biological Invasions 8:509-521

Batra, S. W. T. 1978. Carduus thistle distribution and biological control in the northeastern states. Pages 18-22 in K. E. Frick, editor. Biological control of the genus Carduus in the United States - a progress report. Science and Education Administration, U.S. Department of Agriculture, Washington, D.C., USA.

Bullock, J. M., R. J. Edwards, P. D. Carey, and R. J. Rose. 2000. Geographical separation of two Ulex species at three spatial scales: Does competition limit species' ranges? Ecography 23:257-271.

Byers, J. E. 2000. Competition between two estuarine snails: Implications for invasions of exotic species. Ecology 81:12251239.

Chesson, P. 2000. Mechanisms of maintenance of species diversity. Annual Review of Ecology and Systematics 31:343-366.

Crawley, M. 2002. Statistical computing: an introduction to data analysis using S+. John Wiley and Sons, New York, New York, USA.

Crowe, M. L., and R. S. Bourchier. 2006. Interspecific interactions between the gall-fly Urophora affinis Frfld. (Diptera : Tephritidae) and the weevil Larinus minutus Gyll. (Coleoptera : Curculionidae), two biological control agents released against spotted knapweed, Centaurea stobe L. ssp micranthos. Biocontrol Science and Technology 16:417-430.

Davis, M., et al. 2011. Don't judge species on their origins. Nature 474:153-154.

Desrochers, A. M., J. F. Bain, and S. I. Warwick. 1988. The biology of Canadian weeds 89. Carduus nutans L. and Carduus acanthoides L. Canadian Journal of Plant Science 68:1053-1068

Elton, C. S. 1958. The ecology of invasions by animals and plants. University of Chicago Press, Chicago, Illinois, USA.

Freckleton, R. P., and A. R. Watkinson. 2000. On detecting and measuring competition in spatially structured plant communities. Ecology Letters 3:423-432.

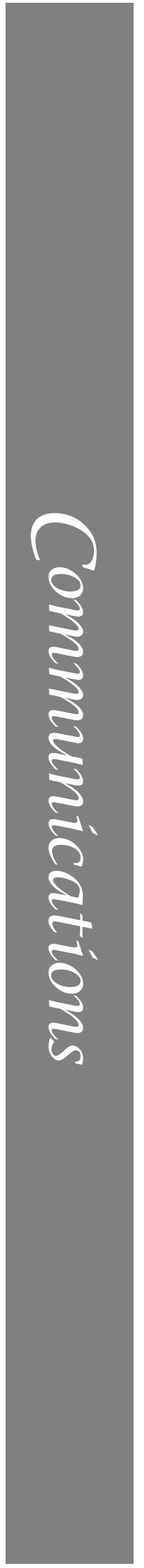


Goldberg, D. E. 1987. Neighborhood competition in an oldfield plant community. Ecology 68:1211-1223.

Goldberg, D. E., and A. M. Barton. 1992. Patterns and consequences of interspecific competition in natural communities: a review of field experiments with plants. American Naturalist 139:771-801.

Griffen, B. D., I. Altman, J. Hurley, and H. Mosblack. 2011. Reduced fecundity by one invader in the presence of another: A potential mechanism leading to species replacement. Journal of Experimental Marine Biology and Ecology 406:6-13.

Griffen, B. D., and J. E. Byers. 2009. Community impacts of two invasive crabs: the interactive roles of density, prey recruitment, and indirect effects. Biological Invasions 11:927-940.

Guo, Q., J. H. Brown, and B. J. Enquist. 1998. Using constraint lines to characterize plant performance. Oikos 83:237-245.

Gurevitch, J., L. L. Morrow, A. Wallace, and J. S. Walsh. 1992. A meta-analysis of competition in field experiments. American Naturalist 140:539-572.

Hoef, J. M. V., and P. L. Boveng. 2007. Quasi-poisson vs. negative binomial regression: How should we model overdispersed count data? Ecology 88:2766-2772.

Inouye, B. D. 2001. Response surface experimental designs for investigating interspecific competition. Ecology 82:26962706.

Johansson, M. E., and P. A. Keddy. 1991. Intensity and asymmetry of competition between plant pairs of different degrees of similarity: an experimental study on 2 guilds of wetland plants. Oikos 60:27-34.

Kubota, Y., and T. Hara. 1996. Allometry and competition between saplings of Picea jezoensis and Abies sachalinensis in a sub-boreal coniferous forest, northern Japan. Annals of Botany 77:529-537.

Laterra, P., and M. E. Bazzalo. 1999. Seed-to-seed allelopathic effects between two invaders of burned Pampa grasslands. Weed Research 39:297-308.

Levine, J. M., P. B. Adler, and S. G. Yelenik. 2004. A metaanalysis of biotic resistance to exotic plant invasions. Ecology Letters 7:975-989.

Lohrer, A. M., and R. B. Whitlatch. 2002. Interactions among aliens: apparent replacement of one exotic species by another. Ecology 83:719-732.

McCarty, M. K., C. J. Scifres, A. L. Smith, and G. L. Horst. 1969. Germination and early seedling development of musk and plumeless thistles. Nebraska Research Bulletin 229. University of Nebraska, Lincoln, Nebraska, USA.

Meekins, J. F., and B. C. McCarthy. 1999. Competitive ability of Alliaria petiolata (garlic mustard, Brassicaceae), an invasive, nonindigenous forest herb. International Journal of Plant Sciences 160:743-752.

Milbrath, L. R., and J. R. Nechols. 2004. Individual and combined effects of Trichosirocalus horridus and Rhinocyllus conicus (Coleoptera: Curculionidae) on musk thistle. Biological Control 30:418-429.
Mooney, H. A., and R. J. Hobbs. 2000. Invasive species in a changing world. Island Press, Washington, D.C, USA.

O'Hara, R. B., and D. J. Kotze. 2010. Do not log-transform count data. Methods in Ecology and Evolution 1:118-122.

R Development Core Team. 2008. R: a language and environment for statistical computing. R Foundation for Statistical Computing, Vienna, Austria. http://www. R-project.org

Ramsay, A., J. Davidson, T. Landry, and G. Arsenault. 2008. Process of invasiveness among exotic tunicates in Prince Edward Island, Canada. Biological Invasions 10:1311-1316.

Rauschert, E. S. J. 2006. Competitive interactions and associations of the invasive thistles Carduus nutans and $C$. acanthoides. Dissertation. Pennsylvania State University, University Park, Pennsylvania, USA.

Rauschert, E. S. J., K. Shea, and O. N. Bjornstad. 2012. Coexistence patterns of two invasive thistle species, Carduus nutans and C. acanthoides, at three spatial scales. Biological Invasions 14:151-164.

Ruggiero, D., and K. Shea. 2011. Effects of interspecific competition on early life history of the invasive thistles Carduus nutans and C. acanthoides. Northeastern Naturalist 18:197-206.

Seabloom, E. W., E. T. Borer, V. L. Boucher, R. S. Burton, K. L. Cottingham, L. Goldwasser, W. K. Gram, B. E. Kendall, and F. Micheli. 2003. Competition, seed limitation, disturbance, and reestablishment of California native annual forbs. Ecological Applications 13:575-592.

Sfenthourakis, S., E. Tzanatos, and S. Giokas. 2006. Species cooccurrence: the case of congeneric species and a causal approach to patterns of species association. Global Ecology and Biogeography 15:39-49.

Simberloff, D. 1999. Potential interactions of nonindigenous species: invasional meltdown? Biological Invasions 1:21-32.

Skarpaas, O., and K. Shea. 2007. Dispersal patterns, dispersal mechanisms, and invasion wave speeds for invasive thistles. American Naturalist 170:421-430.

Tilman, D. 1997. Mechanisms of plant competition. Pages 239261 in M. J. Crawley, editor. Plant Ecology. Blackwell, Malden, Massachusetts, USA.

Warwick, S. I., B. K. Thompson, and L. D. Black. 1990. Comparative growth response in Carduus nutans, Carduus acanthoides, and their F1 hybrids. Canadian Journal of Botany 68:1675-1679.

White, E. M., J. C. Wilson, and A. R. Clarke. 2006. Biotic indirect effects: a neglected concept in invasion biology. Diversity and Distributions 12:443-455.

Yang, S. A., M. J. Ferrari, and K. Shea. 2011. Pollinator behavior mediates negative interactions between two congeneric invasive plant species. American Naturalist 177:110118.

Zuur, A. F., E. N. Ieno, N. J. Walker, A. A. Saveliev, and G. M. Smith. 2009. Mixed effect models and extensions in ecology with R. Springer-Verlag, New York, New York, USA.

\section{Supplemental Material}

\section{Appendix}

A figure showing the number of flower heads produced in response to the total planting density and the proportion of other species present in the seedling placement experiment (Ecological Archives A022-073-A1). 